\title{
Unusual Presentation of Multi-organ Hydatid Cysts in a Child
}

\author{
İsa Cam1, Özgür Çakır1, Ayşe Tekin Yılmaz², Samet Genez², Yonca Anık \\ ${ }^{1}$ Department of Radiology, Kocaeli University School of Medicine, Kocaeli, Turkey \\ ${ }^{2}$ Department of Infectious Diseases and Clinical Microbiology, Kocaeli University School of Medicine, Kocaeli, Turkey \\ ${ }^{3}$ Clinic of Radiology, Derince Training and Research Hospital, Kocaeli, Turkey
}

A 9-year-old boy presented to the pediatric clinic with symptoms of headache, left-sided diplopia, impaired speech, and nausea. His leukocyte count was $14100 / \mu \mathrm{L}$ with eosinophilia of $3050 / \mu \mathrm{L}$ (21.7\%). Cranial magnetic resonance imaging revealed the presence of a cyst measuring $7 \times 6 \mathrm{~cm}$ in the left parietal region with some mass effect over the adjacent structures and minimal perilesional edema. The lesion was solitary, homogeneous, and spherical with well-defined borders and no contrast enhancement (Figure 1a). Initial radiological diagnosis was that of hydatid disease. Subsequent thoracic radiography revealed multiple, well-delineated, round opacities (Figure 1b). Multiple cystic lesions were also detected on the liver upon abdominal magnetic resonance imaging and ultrasound imaging (Figure 1c). Echinococcal enzyme-linked immunosorbent assay as well as indirect hemagglutination and and hydatid cyst antibody tests showed positive results, confirming the diagnosis of hydatid disease. Oral albendazole treatment at $400 \mathrm{mg}$ was initiated along with $4 \times 3 \mathrm{mg}$ of intravenous dexamethasone to treat perilesional edema associated with the brain lesion. After 7 days of presentation, the brain cyst was surgically removed without any complications. Pathology was consistent with that of a cerebral hydatid cyst.

Albendazole was continued at a dose of $10 \mathrm{mg} / \mathrm{kg} /$ day. After 56 months of treatment, follow-up images of the lesion sites were obtained. Brain magnetic resonance imaging revealed encephalomalacic changes at the surgical site; however, no recurrence of the hydatid cyst was detected (Figure 2a). Total regression in both the lungs (Figure $2 b$ ) and liver (Figure 2c) was observed with no recurrence of the hydatid cyst. Informed consent for publication was obtained from the patient's family.

This case describes an extremely rare presentation of hydatid disease. Only $1 \%$ of hydatid disease cases have been reported to involve the central nervous system, with the lesions generally being adjacent to the middle cerebral artery (1). Hydatid disease accounts for only $1 \%-2 \%$ of pediatric cerebral space-occupying lesions (2), and the most common symptoms associated with primary intracranial cysts include headache, papilledema, diplopia, nausea, and vomiting, some of which were observed upon presentation of our case. Symptoms caused due to increased intracranial pressure may also
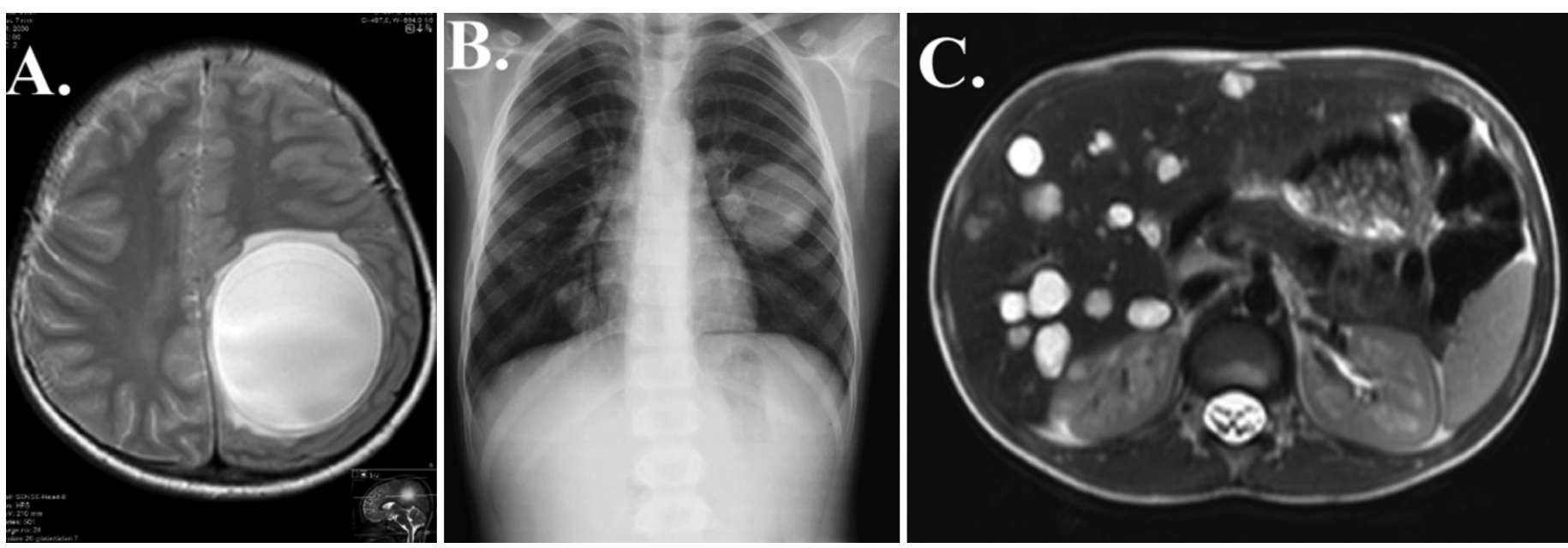

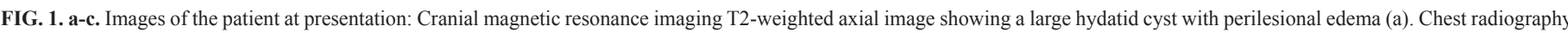
showing multiple hydatid cysts (b). T2-weighted axial image at the level of the liver showing multiple hydatid cystic lesions (c).

Address for Correspondence: İsa Cam, Department of Radiology, Kocaeli University School of Medicine, Kocaeli, Turkey e-mail: dr.isa.cam@gmail.com ORCID: orcid.org/0000-0001-9551-2364

Received: 6 February $2019 \quad$ Accepted: 20 May 2019•DOI: 10.4274/balkanmedj.galenos.2019.2019.2.31

Available at www.balkanmedicaljournal.org

Cite this article as:

Cam İ, Çakır Ö, Tekin Yılmaz A, Genez S, Anık Y. Unusual Presentation of Multi-organ Hydatid Cysts in a Child. Balkan Med J 2019;36:292-3

${ }^{\circ}$ Copyright 2019 by Trakya University Faculty of Medicine / The Balkan Medical Journal published by Galenos Publishing House. 

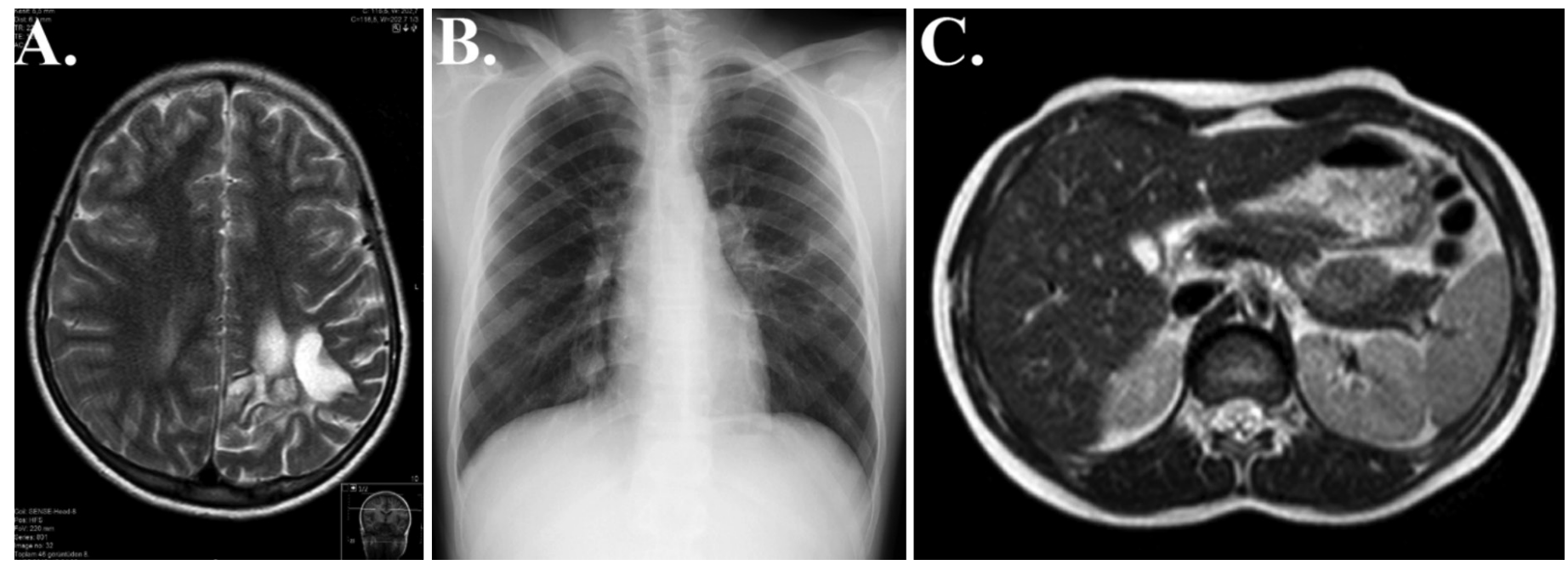

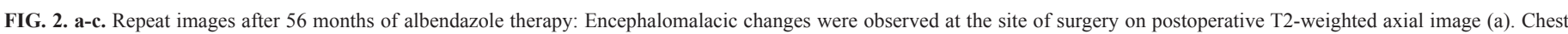
radiography showing complete regression of hydatid cysts (b). T2-weighted axial image of the liver with total regression of hydatid cysts (c).

manifest (2). Hydatid disease generally involves the liver $(50 \%$ $70 \%$ ) and less commonly the lungs (20\%-30\%); cysts have also been reported in other tissues, including the heart, genitourinary system, and soft and skeletal tissues. Hydatid disease typically demonstrates characteristic imaging findings $(1,3)$. Additional diagnostic testing should include serological testing even though it has a variable sensitivity ranging $50 \%-98 \%(3,4)$. Therefore, negative serological tests cannot be used to rule out hydatid disease. In the present study, albendazole therapy was started because it has been suggested to reduce disease recurrence $(2,3)$.

Diagnosing hydatid disease requires abdominal ultrasound imaging and chest radiography to investigate the liver and lung. Computed tomography and magnetic resonance imaging are useful techniques for diagnosing disseminated disease. Serological tests are helpful but are not diagnostic and cannot exclude hydatid disease. Management of disseminated hydatid disease is complex and requires a multidisciplinary approach. Albendazole therapy should be initiated because of its efficacy in preventing hydatid disease recurrence.

Conflict of Interest: No conflict of interest was declared by the authors.

\section{REFERENCES}

1. Pedrosa I, Saíz A, Arrazola J, Ferreirós J, Pedrosa CS. Hydatid disease: radiologic and pathologic features and complications. Radiographics 2000;20:795-817.

2. Tanki H, Singh H, Raswan US, Bhat AR, Kirmani AR, Ramzan AU. Pediatric Intracranial Hydatid Cyst: A Case Series with Literature Review. Pediatr Neurosurg 2018;53:299-304.

3. Mandal S, Mandal MD. Human cystic echinococcosis: epidemiologic, zoonotic, clinical, diagnostic and therapeutic aspects. Asian Pac J Trop Med 2012;5:253-60.

4. Berberian G, Rosanova T, Inda L, Sarkis C, Questa H, Paulin P, et al. Echinococcosis in children: Experience in a tertiary care hospital outside the endemic area. Arch Argent Pediatr 2017;115:282-6. 